\title{
Pengaruh Kepemimpinan Transformasional Dan Budaya Organisasi Terhadap Kepuasan Kerja Serta Dampaknya Pada Kinerja Karyawan
}

\author{
Rizki Wahyuniardi, Hepytisa Renaldo Nababan* \\ Teknik Indusri, Fakultas Teknik Industri Universitas Pasundan Bandung \\ Jl. Setiabudhi No 193, Bandung 40153 \\ *Korespondensi Penulis, surel: hepytisa.renaldo@gmail.com
}

\begin{abstract}
This study aims to analyze employee performance. Employee performance is the result of thinking and energy from an employee to the existing job, can be tangible, seen, employee performance by some factors that are Transformational Leadership, Organizational Culture, and Job Satisfaction. Referring to the purpose of research that is done is to analyze and analyze various variables, then this research is descriptive and verificative. In descriptive analysis explained the dependent variables on which the theory is based. The verification analysis is used. Structural Equation Modeling (SEM) with the help of Lisrel program.
\end{abstract}

Keywords: Organizational Culture, Transformational Leadership, Job Satisfaction, Employee Performance

\begin{abstract}
Abstrak
Penelitian ini bertujuan untuk menganalisis kinerja karyawan. Kinerja karyawan merupakan hasil olah pikir dan tenaga dari seorang karyawan terhadap pekerjaan yang dilakukannya, dapat berwujud, dilihat, dihitung jumlahnya. Kinerja karyawan dipengaruhi oleh beberapa faktor yaitu Kepemimpinan Transformasional, Budaya Organisasi dan Kepuasan Kerja. Mengacu pada tujuan penelitian yang dilakukan yaitu untuk menganalisis beberapa variabel - variabel penelitian yang diteliti maka penelitian ini bersifat deskriptif dan verifikatif. Dalam analisa deskriptif dijelaskan tentang variabel - variabel independen maupun variabel - variabel dependen yang menjadi landasan teori. Dalam penelitian ini, analisa verifikatif yang digunakan adalah statistik Structural Equation Modelling (SEM) dengan bantuan program Lisrel.
\end{abstract}

Kata Kunci : Budaya Organisasi, Kepemimpinan Transformasional, Kepuasan Kerja, Kinerja Karyawan

\section{Pendahuluan}

Tiap perusahaan pasti memiliki target atau tujuan yang ingin dicapai dalam suatu periode tertentu untuk mempertahankan kelangsungan hidup perusahaan tersebut [1] [2]. Target atau tujuan tersebut tidak akan mungkin tercapai tanpa sumber daya yang memadai [3]. Salah satu sumber daya yang memiliki peran penting dalam pencapaian tujuan perusahaan maupun organisasi adalah sumber daya manusia [4].

Ada beberapa masalah terkait dengan kinerja karyawan yang dialami oleh perusahaan yang merupakan distributor utama produk CANON (copier, fax, micrographic). Perusahaan adalah memiliki 180 karyawan yang dibagi menjadi 5 divisi (business image solution, graphic image solution, garment and textile, GCC cutting, dan photo print). Dari observasi dan data yang didapat dari perusahaan terdapat beberapa masalah terkait kinerja karyawan, yaitu banyaknya karyawan yang absen atau tidak 
hadir tanpa izin. Berikut data absensi karyawan perusahaan dari 5 divisi sejak bulan Juli 2016 - Maret 2017.

Tabel 1 Tingkat Kehadiran Karyawan Dari 5 Divisi Perusahaan

\begin{tabular}{lccccc}
\hline \multirow{2}{*}{ Bulan } & \multicolumn{2}{c}{ Keterangan Absensi } & & \\
\cline { 2 - 4 } & Alpha/Mangkir & $\begin{array}{c}\text { Cuti } \\
\text { Mendadak }\end{array}$ & $\begin{array}{c}\text { Surat } \\
\text { Dokter }\end{array}$ & Jumlah & Persentase \\
\hline Juli & 49 & 25 & 17 & 91 & $2,66 \%$ \\
Agustus & 38 & 23 & 14 & 75 & $1,89 \%$ \\
September & 40 & 28 & 19 & 87 & $2,30 \%$ \\
Oktober & 33 & 22 & 12 & 67 & $1,77 \%$ \\
November & 47 & 24 & 10 & 81 & $2,04 \%$ \\
Desember & 45 & 25 & 12 & 82 & $2,16 \%$ \\
Januari & 32 & 26 & 15 & 73 & $1,84 \%$ \\
Februari & 39 & 24 & 14 & 77 & $2,13 \%$ \\
Maret & 34 & 22 & 10 & 66 & $1,66 \%$ \\
Total & 357 & 219 & 123 & 699 & $18,45 \%$ \\
\hline
\end{tabular}

Sumber: Perusahaan, 2017

Dari persentase data pada Tabel 1 di atas yang didapat dari pembagian jumlah karyawan yang tidak hadir dengan jumlah hari kerja maka dapat dilihat bahwa mayoritas karyawan yang tidak hadir adalah karyawan yang alpha/ mangkir. Untuk bulan Juli 2016 total karyawan yang tidak dapat hadir itu sebanyak 91 kasus, jika ditotal keseluruhan karyawan yang alphal mangkir dari bulan Juli 2016 s/d Maret 2017 sebanyak 357 kasus, pada data tersebut tidak hanya menampilkan absensi karyawan yang alpha/ mangkir saja, namun ada karyawan yang mengambil cuti mendadak dan juga sakit (surat dokter). Jika ditotal keseluruhan kasus absensi karyawan dari bulan Juli 2016 s/d Maret 2017 terdapat 699 kasus karyawan yang tidak hadir atau sekitar 18,45\%. Jika banyaknya karyawan yang tidak hadir ini akan mengganggu proses penjualan produk. Karena target perusahaan untuk menjual semua produk akan tidak tercapai jika banyaknya karyawan yang tidak hadir.

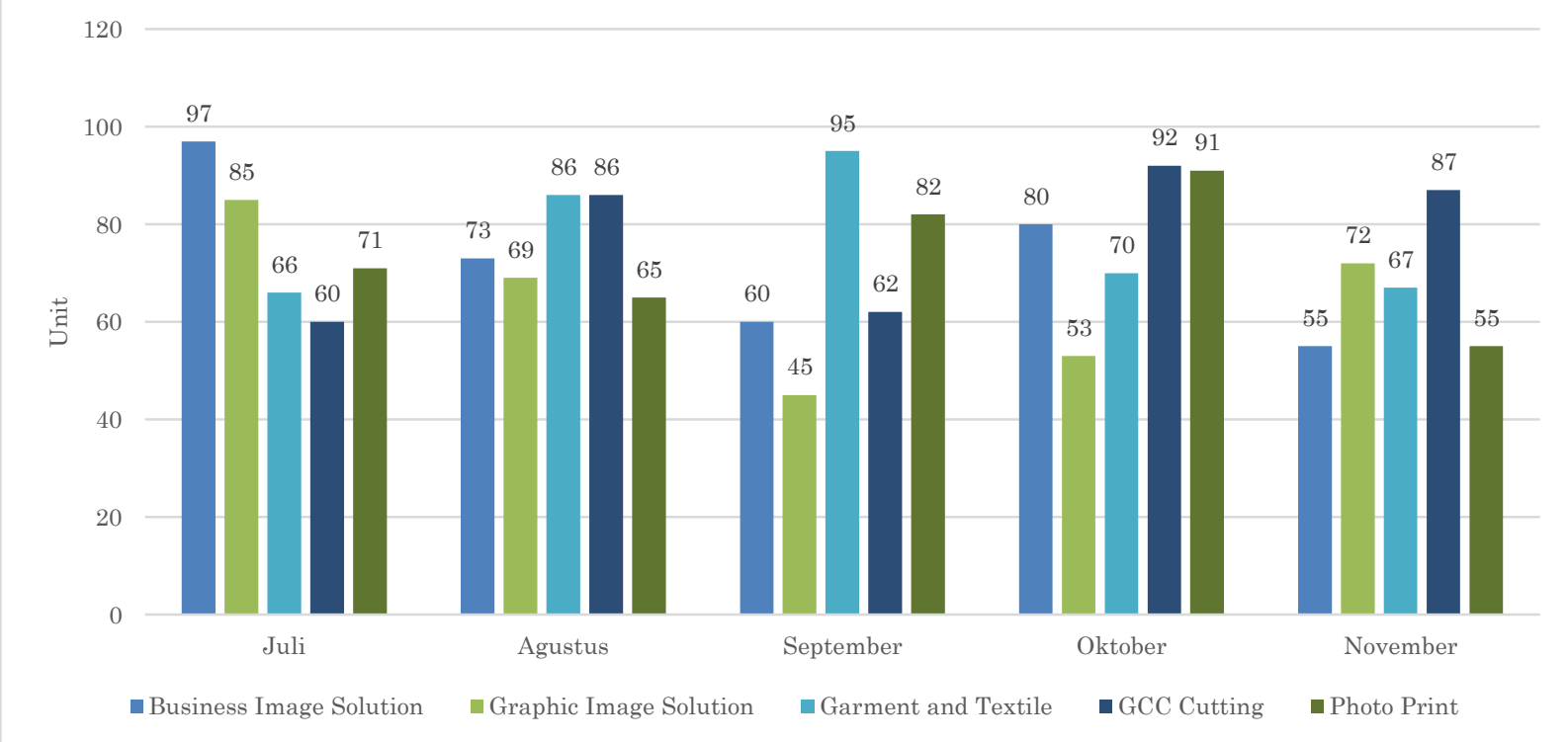

Sumber: Perusahaan, 2017

Gambar 1 Laporan Penjualan Karyawan PT."Z” Bandung 
Gambar 1 menjelaskan total penjualan produk dari bulan Juli 2016 - November 2016 yang dilakukan oleh karyawan Perusahaan. Dari gambar tersebut dapat dilihat ketidak stabilan penjualan produk yang dilakukan oleh karyawan. Divisi business image solution pada bulan Juli 2016 total penjualan sebanyak 97 unit namun terjadi penurunan 2 (dua) bulan kemudian dan naik kembali pada bulan Oktober dan terjadi penurunan yang sangat signifikan pada bulan November. Data tersebut menunjukkan tidak stabilannya kinerja karyawan dalam penjualan produk yang dikarenakan banyaknya karyawan yang tidak hadir, dan hal ini terjadi pula pada divisi lainnya. Dengan demikian apabila kinerja karyawan tidak dikelola dengan baik akan berdampak buruk bagi perusahaan.

Kinerja karyawan yang merupakan hasil olah pikir dan tenaga dari seorang karyawan terhadap pekerjaan yang dilakukannya, dapat berwujud, dilihat, dihitung jumlahnya. Kinerja karyawan dipengaruhi oleh banyak faktor salah satunya adalah kepuasan kerja [5]. Jika kepuasan kerja telah dipenuhi, maka kinerja karyawan juga akan meningkat. Hal ini sesuai dengan pendapat Leroy, et al. [6], yaitu kepuasan kerja memengaruhi kinerja seseorang. Apabila kepuasan kerja yang dirasakan oleh karyawan rendah akan memberikan dampak negatif terhadap perusahaan karena kinerja karyawan tersebut akan menurun dan akibatnya kinerja perusahaan akan terganggu dan sebaliknya [7].

Dari penelitian sebelumnya terdapat beberapa faktor yang memengaruhi kepuasan kerja dan kinerja karyawan di antaranya adalah Kepemimpinan Tranformasional. Gaya kepemimpinan menjadi faktor penting yang memengaruhi perilaku kerja seperti kinerja karyawan. Gaya kepemimpinan secara langsung memengaruhi kepuasan kerja melalui kecermatannya dalam menciptakan pekerjaan dan lingkungan kerja yang menarik, pelimpahan tanggung jawab serta penerapan peraturan dengan baik [8].

Selanjutnya adalah Budaya Organisasi Satwika and Himam [9] menjelaskan bahwa semakin tinggi budaya organisasi maka semakin tinggi pula kepuasan kerja karyawan, sebaliknya apabila rendahnya budaya organisasi maka kepuasan kerja semakin rendah. Dengan kepemimpinan transformasional dan budaya organisasi ini diharapkan para pemimpin perusahaan dapat memberi dorongan dan motivasi agar para karyawan dapat bekerja lebih baik dan juga dengan adanya budaya organisasi ini dapat memberikan kebiasaan yang baik bagi karyawan agar dapat bekerja lebih produktif sehingga dapat mencapai tujuan perusahaan. Dengan demikian maka peneliti mencoba untuk meneliti tentang "Analisis Pengaruh Kepemimpinan Transformasional dan Budaya Organisasi Terhadap Kepuasan Kerja serta dampak pada Kinerja Karyawan di Perusahaan".

Berdasarkan latar belakang yang sudah dijelaskan di atas penulis mengetahui bahwa banyak karyawan yang alpha/mangkir yang menyebabkan tidak stabilnya proses penjualan dan ada beberapa faktor yang dapat memengaruhi kinerja karyawan. Maka dari itu penulis dapat merumuskan beberapa hipotesis yaitu Kepemimpinan Transformasional dan Budaya Organisasi berpengaruh terhadap Kepuasan Kerja dan berdampak pada Kinerja Karyawan; Kepemimpinan Transformasional dan Budaya Organisasi berpengaruh kepada Kepuasan Kerja; Kepemimpinan Transformasional dan Budaya Organisasi berpengaruh kepada Kinerja Karyawan; serta Kepemimpinan Transformasional dan Budaya Organisasi secara simultan berpengaruh terhadap Kinerja Karyawan. 


\section{Metode Penelitian}

Metode yang digunakan dalam penelitian ini adalah metode explanatory survey yaitu suatu survei yang digunakan untuk menjelaskan hubungan kausalitas antara variabel yang akan diteliti melalui pengujian hipotesis. Sedangkan tipe hubungan antara variabel yang digunakan dalam penelitian ini adalah kausalitas yaitu variabel independen/variabel bebas memengaruhi variabel dependen/variabel terikat. Penelitian explanatory mengacu pada hipotesis yang akan diuji terhadap fenomena yang terjadi. Fenomena tersebut dapat dilihat dalam objek penelitian yaitu karyawan di perusahaan.

Mengacu pada tujuan penelitian yang akan dilakukan yaitu untuk mengetahui dan mengkaji lebih dalam terhadap variabel - variabel penelitian yang akan diteliti yaitu pengaruh Kepemimpinan Transformasional, Budaya Organisasi terhadap Kepuasan Kerja serta dampaknya terhadap Kinerja Karyawan, maka penelitian ini bersifat deskriptif dan verifikatif. Dalam analisa deskriptif akan dijelaskan tentang variabel variabel independen maupun variabel - variabel dependen yang menjadi landasan teori dalam penelitian yang memuat teori - teori dari variabel yang diteliti yaitu Kepemimpinan Tranformasional, Budaya Organisasi, Kepuasan Kerja dan Kinerja Karyawan pada Perusahaan. Sedangkan analisa verifikatif dilaksanakan untuk menguji hipotesis dengan menggunakan alat uji statistika ([10] dalam Uma Sekaran, 2006). Sifat penelitian verifikatif adalah untuk menguji kebenaran suatu hipotesis yang dilaksanakan melalui pengumpulan data di lapangan tentang variabel-variabel yang akan diteliti. Dalam penelitian ini, analisa verifikatif yang digunakan adalah statistik Structural Equation Model (SEM). Analisis SEM merupakan teknik analisis data multivariat yang memadukan analisa jalur dengan analisa faktor (Hair, J.F. R.F. Anderson, 1995 dalam [11]). Model konseptual penelitian diperlihatkan pada Gambar 2.

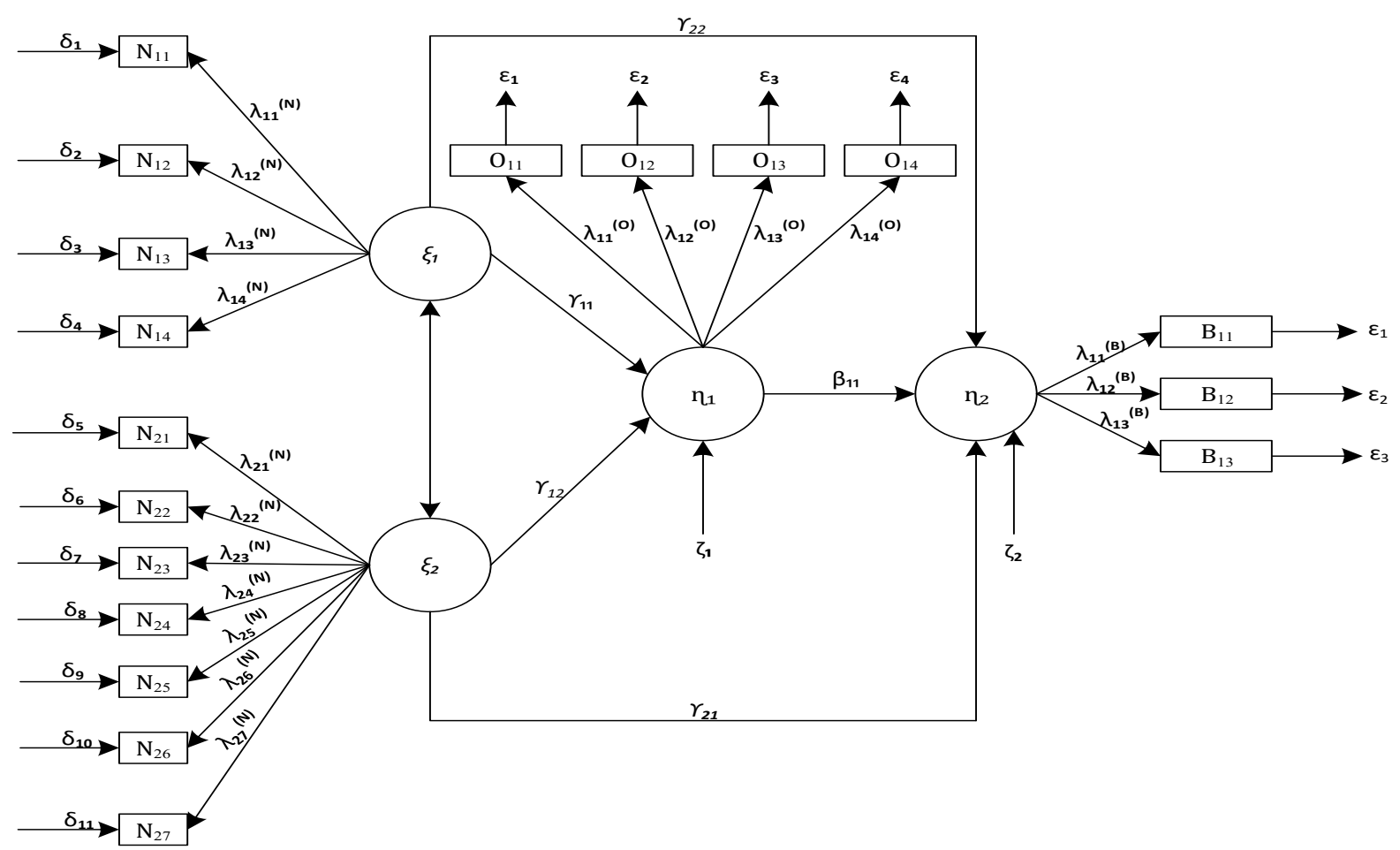

Gambar 2 Struktur Analisis Variabel Penelitian Secara Keseluruhan (SEM) 
Pada Gambar 2 dapat dilihat model SEM dengan menggunakan lambang-lambang disetiap variabel dan indikatornya (dimensi). Untuk penjelasan lambang-lambang tersebut dapat dilihat pada Tabel 2.

Tabel 2 Lambang Statistik Untuk Dimensi dan Variabel yang Diteliti

\begin{tabular}{cccc}
\hline Lambang & Dimensi & Lambang & Variabel \\
\hline $\mathrm{N}_{11}$ & Pengaruh Ideal & & Kepemimpinan \\
$\mathrm{N}_{12}$ & Motivasi Inspirasional & $\xi_{1}$ & Transformasional \\
$\mathrm{N}_{13}$ & Stimulasi Intelektual & & \\
$\mathrm{N}_{14}$ & Perhatian Individu & & \\
$\mathrm{N}_{21}$ & Shared Value (Nilai Bersama) & & \\
$\mathrm{N}_{22}$ & Structure (Struktur) & & \\
$\mathrm{N}_{23}$ & System (Sistem) & $\xi_{2}$ & Budaya Organisasi \\
$\mathrm{N}_{24}$ & Staff (Staf) & & \\
$\mathrm{N}_{25}$ & Skills (Keterampilan) & & \\
$\mathrm{N}_{26}$ & Style (Gaya) & & \\
$\mathrm{N}_{27}$ & Strategy (Strategi) & & \\
$\mathrm{O}_{11}$ & Turnover & $\eta_{1}$ & Kepuasan Kerja \\
$\mathrm{O}_{12}$ & Tingkat Kehadiran (absen) Kerja & & \\
$\mathrm{O}_{13}$ & Umur & & \\
$\mathrm{O}_{14}$ & Tingkat Pekerjaan (Jabatan) & & Kinerja Karyawan \\
$\mathrm{B}_{11}$ & Kemampuan & $\eta_{2}$ & \\
$\mathrm{~B}_{12}$ & Motivasi & & \\
$\mathrm{B}_{13}$ & Pengetahuan Pekerjaan & & \\
\hline
\end{tabular}

\section{Hasil dan Pembahasan}

Pada penelitian ini responden yang akan diteliti adalah seluruh karyawan perusahaan yang berjumlah 180 orang. Gambar 3 memperlihatkan evaluasi terhadap koefisien - koefisien atau parameter - parameter yang menunjukkan hubungan kausal atau pengaruh satu variabel laten terhadap variabel laten lainnya berdasarkan Standardized Coefficient.

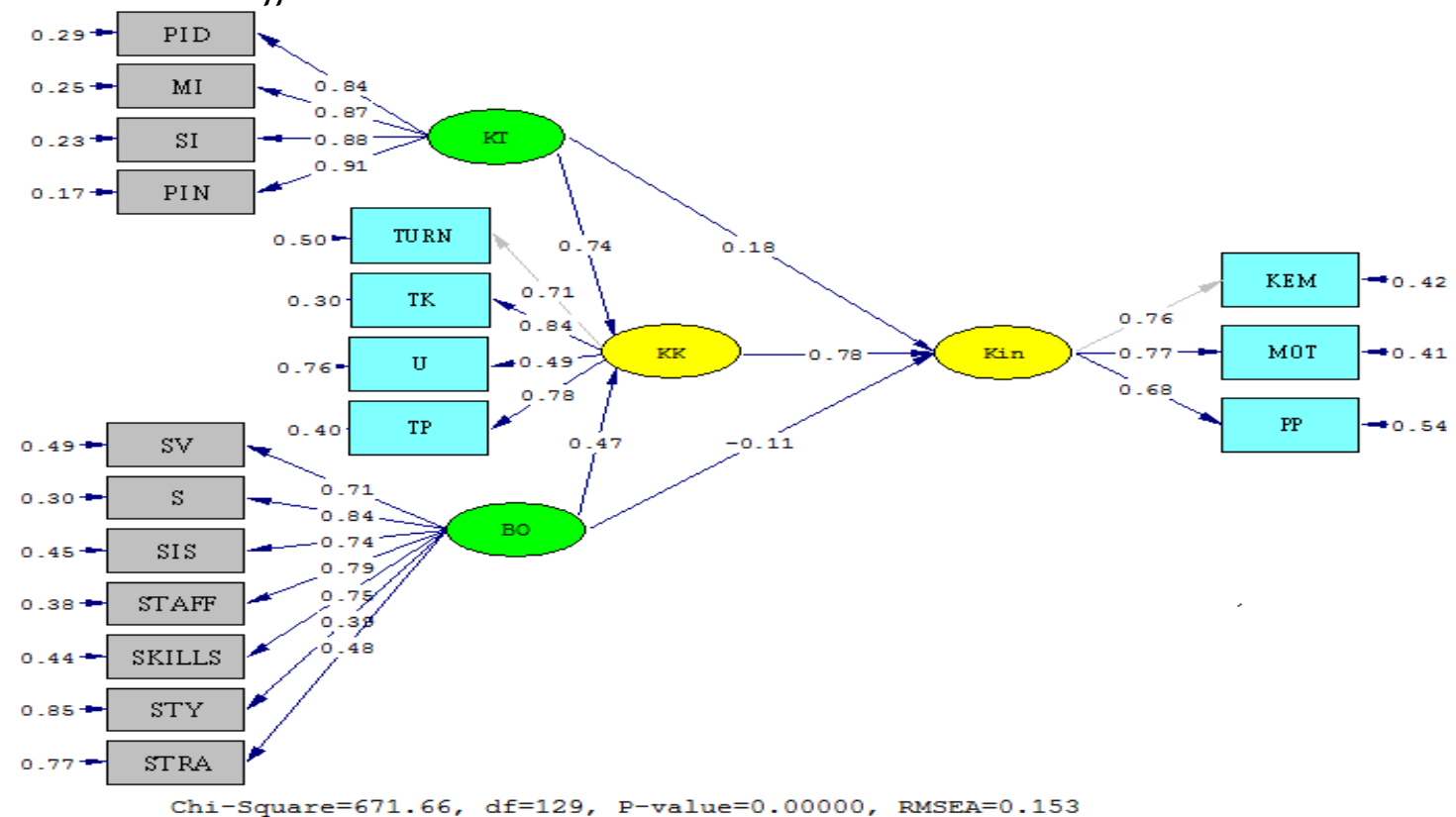

Gambar 3 Hasil Estimasi Standardized Coefficient 
Sedangkan pada Gambar 4 diperlihatkan evaluasi terhadap koefisien - koefisien atau parameter - parameter yang menunjukkan hubungan kausal atau pengaruh satu variabel laten terhadap variabel laten lainnya berdasarkan t-values. Secara ringkas hasil perhitungan koefisien - koefisien tersebut disajikan dalam Tabel 3.

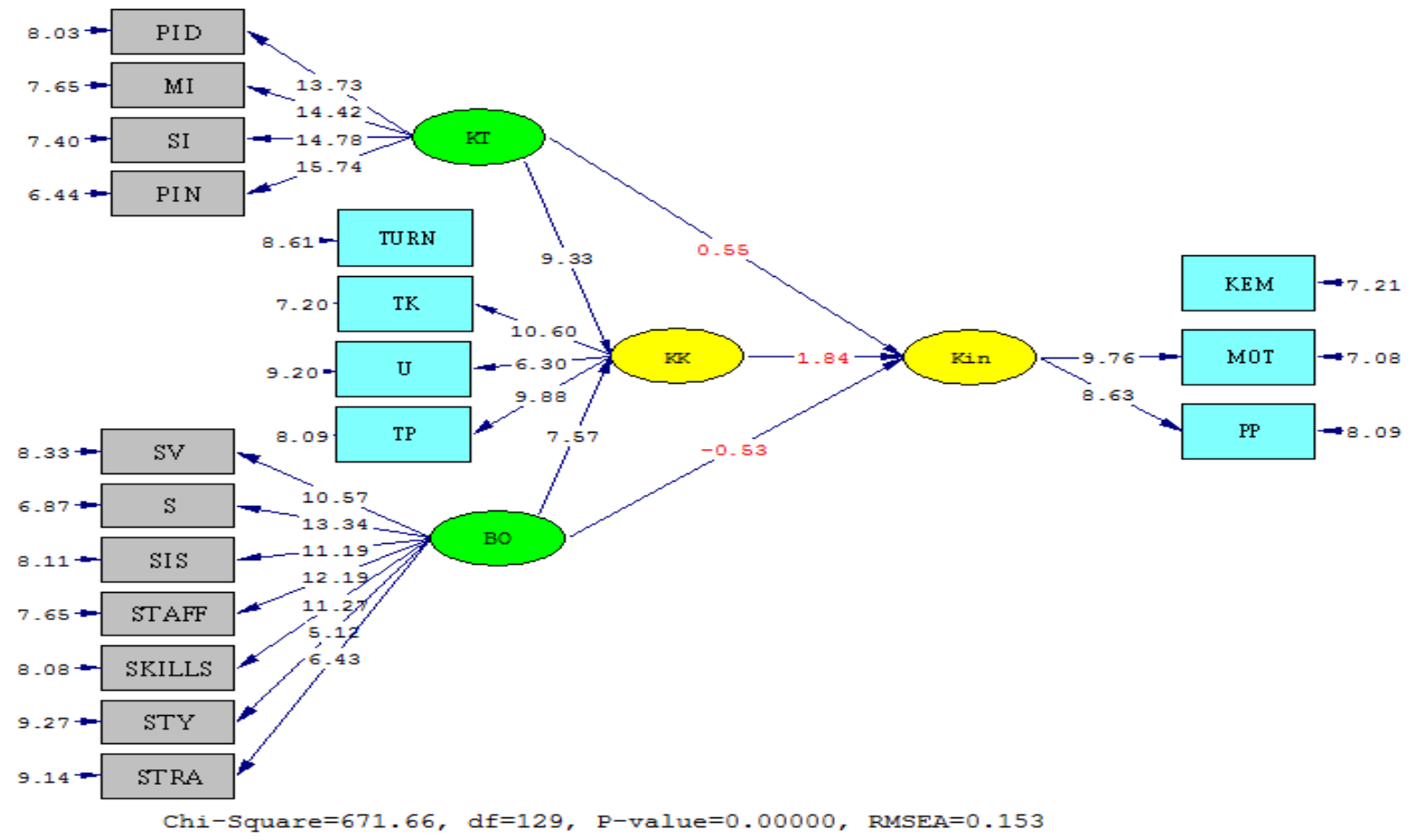

Gambar 4 Hasil Estimasi t-values

Tabel 3 Nilai t, Nilai Standardized Coefficient, dan Nilai $R$-Square

\begin{tabular}{ccccc}
\hline Persamaan Struktural & Pengaruh & Nilai t & SPC & $\mathrm{R}^{2}$ \\
\hline$\eta_{1}=\left(\gamma_{11} \times \xi_{1}\right)+\left(\left(\gamma_{12} \times \xi_{2}\right)+\zeta_{1}\right.$ & $\begin{array}{c}\xi_{1} \text { terhadap } \eta_{1} \\
\text { (KT--> KK) } \\
\xi_{2} \text { terhadap } \eta_{1} \\
\text { (BO--> KK) }\end{array}$ & 9.33 & 0.74 & 0.57 \\
$\begin{array}{l}\xi_{1} \text { terhadap } \eta_{2} \\
\text { (KT--> Kin) }\end{array}$ & 0.55 & 0.47 & \\
$\begin{array}{l}\xi_{2} \text { terhadap } \eta_{2} \\
\text { (BO--> Kin) } \\
\begin{array}{c}\eta_{1} \text { terhadap } \eta_{2} \\
\text { (KK--> Kin) }\end{array}\end{array}$ & 0.53 & 0.18 & 0.71 \\
\hline
\end{tabular}

Kriteria pengujian signifikan di dalam SEM didasarkan atas nilai titik kritis sebesar 1,97 di mana nilai $t$ (t-value) yang lebih besar dari atau sama dengan titik kritis (t-value $\geq 1,97$ ) menunjukkan bahwa nilai parameter tersebut signifikan secara statistik. Pada kolom berikutnya berisi hasil estimasi koefisien regresi yang telah dibakukan (standardized coefficients) antara variabel laten satu dengan variabel laten lainnya. Sedangkan pada kolom $\mathrm{R}^{2}$ berisi nilai - nilai koefisien determinasi.

Berdasarkan Tabel 3 dapat diketahui bahwa Kepemimpinan Transformasional ( $\left.\xi_{1}\right)$ berpengaruh secara signifikan terhadap Kepuasan Kerja ( $\left.\mathrm{n}_{1}\right)$ sebesar 0,74 dengan nilai t 
lebih besar dari nilai kritis $(9,33 \geq 1,97)$. Budaya Organisasi $\left(\xi_{2}\right)$ berpengaruh secara signifikan terhadap Kepuasan Kerja (n1) sebesar 0,47 dengan nilai $t$ lebih besar dari nilai kritis $(7,57 \geq 1,97)$.

Kepemimpinan Transformasional $\left(\xi_{1}\right)$ tidak berpengaruh secara signifikan terhadap Kinerja Karyawan $\left(\mathrm{n}_{2}\right)$ sebesar 0,18 dengan nilai t lebih kecil dari nilai kritis $(0,18 \leq 1,97)$. Budaya Organisasi $\left(\xi_{2}\right)$ tidak berpengaruh secara signifikan terhadap Kinerja Karyawan ( $\left.\eta_{2}\right)$ sebesar -0,11 dengan nilai t lebih kecil dari nilai kritis $(-0,53 \leq$ 1,97), dan Kepuasan Kerja ( $\left.\mathrm{n}_{1}\right)$ tidak berpengaruh signifikan terhadap Kinerja Karyawan (n2) sebesar 0,78 dengan nilai t lebih kecil dari nilai kritis $(1,84 \leq 1,97)$.

Kriteria pengujian signifikan di dalam SEM didasarkan atas nilai titik kritis sebesar 1,97 di mana nilai t (t-value) yang lebih besar dari atau sama dengan titik kritis (t-value $\geq 1,97$ ) menunjukkan bahwa nilai parameter tersebut signifikan secara statistik. Pada kolom berikutnya berisi hasil estimasi koefisien regresi yang telah dibakukan (standardized coefficients) antara variabel laten satu dengan variabel laten lainnya. Sedangkan pada kolom $\mathrm{R}^{2}$ berisi nilai - nilai koefisien determinasi.

Berdasarkan diagram jalur dapat diketahui bahwa Kepemimpinan Transformasional $\left(\xi_{1}\right)$ berpengaruh secara signifikan terhadap Kepuasan Kerja $\left(\eta_{1}\right)$ sebesar 0,74 dengan nilai $t$ lebih besar dari nilai kritis $(9,33 \geq 1,97)$. Budaya Organisasi $\left(\xi_{2}\right)$ berpengaruh secara signifikan terhadap Kepuasan Kerja $\left(\eta_{1}\right)$ sebesar 0,47 dengan nilai t lebih besar dari nilai kritis $(7,57 \geq 1,97)$.

Kepemimpinan Transformasional $\left(\xi_{1}\right)$ tidak berpengaruh secara signifikan terhadap Kinerja Karyawan $\left(\mathrm{n}_{2}\right)$ sebesar 0,18 dengan nilai t lebih kecil dari nilai kritis $(0,55 \leq 1,97)$. Budaya Organisasi $\left(\xi_{2}\right)$ tidak berpengaruh secara signifikan terhadap Kinerja Karyawan ( $\left.\eta_{2}\right)$ sebesar -0,11 dengan nilai t lebih kecil dari nilai kritis $(-0,53 \leq$ 1,97), dan Kepuasan Kerja ( $\left.\eta_{1}\right)$ tidak berpengaruh signifikan terhadap Kinerja Karyawan (n2) sebesar 0,78 dengan nilai t lebih kecil dari nilai kritis $(1,84 \leq 1,97)$.

Kedua gambar diagram jalur di atas juga menjelaskan hasil estimasi koefisien jalur dan nilai $t$. Untuk melihat lebih detail tentang besar pengaruh langsung dan tidak langsung dari masing-masing variabel bebas terhadap variabel terikat, sehingga secara statistik dinyatakan berpengaruh atau tidak berpengaruh.

Model dekomposisi adalah model yang menekankan pada pengaruh yang bersifat kausalitas antar variabel, baik pengaruh langsung maupun tidak langsung dalam kerangka path analysis, dalam hal ini pengaruh Kepemimpinan Transformasional $\left(\xi_{1}\right)$ terhadap Kinerja Karyawan $\left(\eta_{2}\right)$ melalui Kepuasan Kerja $\left(\eta_{1}\right)$, demikian juga, pengaruh Budaya Organisasi $\left(\xi_{2}\right)$ terhadap Kinerja Karyawan $\left(\eta_{2}\right)$ melalui Kepuasan Kerja $\left(\eta_{1}\right)$. Besar pengaruh langsung dan tidak langsung variabel eksogen terhadap variabel endogen dapat diketahui dalam Tabel 4 dan Tabel 5.

Tabel 4 Pengaruh Langsung dan Tidak Langsung Sub 1

\begin{tabular}{|c|c|c|c|c|c|c|}
\hline \multirow[t]{2}{*}{$\begin{array}{l}\text { Variabel } \\
\text { Eksogen }\end{array}$} & \multirow[t]{2}{*}{$\begin{array}{l}\text { Koefisien } \\
\text { Jalur }\end{array}$} & \multirow[t]{2}{*}{$\begin{array}{l}\text { Pengaruh } \\
\text { Langsung }\end{array}$} & \multicolumn{2}{|c|}{$\begin{array}{c}\text { Pengaruh Terhadap } \\
\text { Variabel Endogen KK } \\
\text { Melalui (\%) }\end{array}$} & \multirow{2}{*}{$\begin{array}{l}\text { Pengaruh } \\
\text { Tidak } \\
\text { Langsung } \\
(\%) \\
\end{array}$} & \multirow{2}{*}{$\begin{array}{c}\text { Total } \\
\text { Pengaruh } \\
\text { (\%) }\end{array}$} \\
\hline & & & KT & BO & & \\
\hline KT & 0,74 & 54,76 & - & 7,304 & 7,304 & 62,1 \\
\hline $\mathrm{KB}$ & 0,47 & 22,09 & 7,304 & - & 7,304 & 29,4 \\
\hline \multicolumn{6}{|c|}{ Total } & 91,5 \\
\hline
\end{tabular}

Hasil Tabel 4 dapat dinyatakan sebagai berikut Kepemimpinan Transformasional $\left(\xi_{1}\right)$ berpengaruh signifikan terhadap Kepuasan Kerja $\left(\eta_{1}\right)$, dengan total pengaruh sebesar $62,1 \%$, terdiri atas pengaruh langsung sebesar 54,76\% dan pengaruh tidak langsung 
sebesar 7,304\%. Budaya Organisasi $\left(\xi_{2}\right)$ berpengaruh signifikan terhadap Kepuasan Kerja $\left(\eta_{1}\right)$, dengan total pengaruh sebesar $29,4 \%$, terdiri atas pengaruh langsung sebesar $22,09 \%$ dan pengaruh tidak langsung sebesar 7,304\%. Secara keseluruhan, variabel Kepemimpinan Transformasional $\left(\xi_{1}\right)$ dan Budaya Organisasi $\left(\xi_{2}\right)$ berpengaruh signifikan secara simultan terhadap variabel Kepuasan Kerja $\left(\eta_{1}\right)$ sebesar 91,5\%, sedangkan sisanya sebesar 8,5\% dipengaruhi oleh variabel lain yang tidak diamati di dalam penelitian ini.

Tabel 5 Pengaruh Langsung dan Tidak Langsung Sub 2

\begin{tabular}{|c|c|c|c|c|c|c|c|}
\hline \multirow[t]{2}{*}{$\begin{array}{l}\text { Variabel } \\
\text { Eksogen }\end{array}$} & \multirow[t]{2}{*}{$\begin{array}{l}\text { Koefisien } \\
\text { Jalur }\end{array}$} & \multirow{2}{*}{$\begin{array}{l}\text { Pengaruh } \\
\text { Langsung } \\
\quad(\%)\end{array}$} & \multicolumn{3}{|c|}{$\begin{array}{c}\text { Pengaruh Terhadap } \\
\text { Variabel Endogen Kin } \\
\text { Melalui (\%) }\end{array}$} & \multirow{2}{*}{$\begin{array}{c}\text { Pengaruh } \\
\text { Tidak } \\
\text { Langsung } \\
(\%) \\
\end{array}$} & \multirow{2}{*}{$\begin{array}{l}\text { Total } \\
\text { Pengaruh } \\
(\%)\end{array}$} \\
\hline & & & KT & $\mathrm{BO}$ & KK & & \\
\hline KT & 0,18 & 3,24 & - & $-0,42$ & 11,65 & 11,24 & 14,5 \\
\hline KB & $-0,11$ & 1,21 & $-0,42$ & - & $-5,32$ & $-5,74$ & $-4,5$ \\
\hline KK & 0,78 & 60,84 & 11,65 & $-5,32$ & - & 6,33 & 67,2 \\
\hline \multicolumn{7}{|c|}{ Total } & 77,1 \\
\hline
\end{tabular}

Tabel 5 menyatakan bahwa Kepemimpinan Transformasional (そ1) memiliki pengaruh terhadap Kinerja Karyawan (n2), dengan total pengaruh sebesar 14,5\%, terdiri atas pengaruh langsung sebesar 3,24\% dan pengaruh tidak langsung sebesar 11,24\%. Budaya Organisasi (そ2) memiliki pengaruh terhadap Kinerja Karyawan (n2), dengan total pengaruh sebesar $-4,5 \%$, terdiri atas pengaruh langsung sebesar $1,21 \%$ dan pengaruh tidak langsung sebesar -5,74\%. Kepuasan Kerja (n1) memiliki pengaruh terhadap Kinerja Karyawan (n2), dengan total pengaruh sebesar 67,2\%, terdiri atas pengaruh langsung sebesar 60,84\% dan pengaruh tidak langsung sebesar 6,33\%. Secara keseluruhan, variabel Kepemimpinan Transformasional (₹1), Budaya Organisasi (§2), dan Kepuasan Kerja (n1) berpengaruh secara simultan terhadap variabel Kinerja Karyawan (n2) sebesar 77.1\%, sedangkan sisanya sebesar 22,9\% dipengaruhi oleh variabel lain yang tidak diamati di dalam penelitian ini. Hasil penelitian ini sesuai dengan penelitian [3] [5] [7] [8] [9].

\section{Simpulan}

Setelah melewati pengolahan, maka dapat diketahui seberapa besar tingkat signifikansi dan besarnya pengaruh baik secara langsung maupun tidak langsung dari masing-masing variabel eksogen ke variabel endogen melalui hasil estimasi Standardized Coefficient, hasil estimasi t-values maupun dari hasil perhitungan nilai

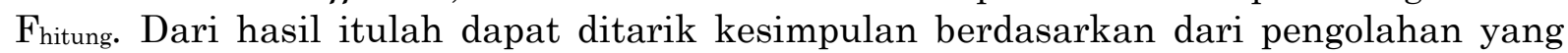
telah dilakukan pada model maka didapatlah hasil di mana, Kepemimpinan Transformasional $\left(\xi_{1}\right)$ berpengaruh signifikan terhadap Kepuasan Kerja $\left(\eta_{1}\right)$, Budaya Organisasi $\left(\xi_{2}\right)$ berpengaruh secara signifikan terhadap Kepuasan Kerja $\left(\eta_{1}\right)$, Kepemimpinan Transformasional $\left(\xi_{1}\right)$ tidak berpengaruh secara signifikan terhadap Kinerja Karyawan ( $\mathrm{n}_{2}$ ). Budaya Organisasi $\left(\xi_{2}\right)$ tidak berpengaruh secara signifikan terhadap Kinerja Karyawan $\left(\eta_{2}\right)$ dan Kepuasan Kerja $\left(\eta_{1}\right)$ tidak berpengaruh signifikan terhadap Kinerja Karyawan (n2).

Dengan demikian untuk meningkatkan Kinerja Karyawan yang ada di perusahaan dapat dilakukan dengan cara meningkatkan Kepuasan Kerja karyawannya. Dengan meningkatnya Kepuasan Kerja maka Kinerja Karyawan akan meningkat hal ini sesuai dengan [4], yaitu kepuasan kerja memengaruhi kinerja seseorang, atau dengan meningkatkan gaya Kepemimpinan Transformasional dan Budaya Organisasi secara 
bersama-sama. Untuk selanjutnya, penelitian dapat dilakukan dengan mengubah variabel-variabel terikat lainnya yang dianggap berpengaruh terhadap kinerja perusahaan.

\section{Referensi}

[1] S. N. Yulindar, "Pengaruh Ukuran Perusahaan dan Profitabilitas Terhadap Nilai Perusahaan pada PT. Semen Indonesia Tbk," 2017.

[2] H. Jaya, "Analisa Peranan Anggaran Biaya Operasional Sebagai Alat Perencanaan Dan Pengendalian Laba: Studi Kasus Pada PT. Adhya Tirta Batam," MEASUREMENT, vol. 8, 2016.

[3] D. G. Verasari, "Pengaruh Kepemimpinan Transformasional dan Motivasi Kerja terhadap Kepuasan Kerja pada Karyawan pada Bank BCA," Jurnal Ilmiah Psikologi, vol. 10, 2017.

[4] R. F. Fakhri and I. Djastuti, "Pengaruh Kompensasi Dan Pelatihan Terhadap Kinerja Karyawan Dengan Kepuasan Kerja Sebagai Variabel Intervening (Studi Pada PT. Audio Sumitomo Technology (Ast) Indonesia)," Fakultas Ekonomika dan Bisnis, 2015.

[5] I. A. Brahmasari and A. Suprayetno, "Pengaruh Motivasi Kerja, Kepemimpinan dan Budaya Organisasi terhadap Kepuasan Kerja Karyawan Serta Dampaknya pada Kinerja Perusahaan (Studi Kasus Pada PT. Pei Hai International Wiratama Indonesia)," Jurnal Manajemen dan Kewirausahaan, vol. 10, pp. 124-135, 2009.

[6] H. Leroy, F. Anseel, W. L. Gardner, and L. Sels, "Authentic Leadership, Authentic Followership, Basic Need Satisfaction, and Work Role Performance: A Cross-Level Study," Journal of Management, vol. 41, pp. 1677-1697, 2015.

[7] M. Indrasari, "Kepuasan Kerja dan Kinerja Karyawan," Yogyakarta: Indomedia Pusaka, 2017.

[8] I. K. Udayana and I. G. Riana, "Analisis Pengaruh Kepemimpinan Transformasional, Komitmen Organisional dan Imbalan Finansial Terhadap Kepuasan Kerja Karyawan," E-Jurnal Manaj. Unud, vol. 4, pp. 3063-3092, 2015.

[9] P. A. Satwika and F. Himam, "Kinerja Karyawan Berdasarkan Keterbukaan terhadap Pengalaman, Organizational Citizenship Behavior dan Budaya Organisasi," Jurnal Psikologi, vol. 41, pp. 205-217, 2014.

[10] D. Agustriyana, "Analisis Faktor-Faktor Penempatan Karyawan," Jurnal Ekonomi, Bisnis \& Entrepreneurship, vol. 9, pp. 158-178, 2015.

[11] M. Ulum, I. M. Tirta, and D. Anggraeni, "Analisis Structural Equation Modeling (SEM) untuk Sampel Kecil dengan Pendekatan Partial Least Square (PLS)," Pros. Semin. Nas. Mat. Univ. Jember, pp. 1-15, 2014. 